\title{
Perceptions of plagiarism by biomedical researchers: an online survey in Europe and China
}

\author{
Nannan $\mathrm{Yi}^{1,2^{*}}$, Benoit Nemery ${ }^{3}$ and Kris Dierickx ${ }^{2}$
}

\begin{abstract}
Background: Plagiarism is considered as serious research misconduct, together with data fabrication and falsification. However, little is known about biomedical researchers' views on plagiarism. Moreover, it has been argued - based on limited empirical evidence - that perceptions of plagiarism depend on cultural and other determinants. The authors explored, by means of an online survey among 46 reputable universities in Europe and China, how plagiarism is perceived by biomedical researchers in both regions.

Methods: We collected work e-mail addresses of biomedical researchers identified through the websites of 13 reputable universities in Europe and 33 reputable universities in China and invited them to participate in an online anonymous survey. Our questionnaire was designed to assess respondents' views about plagiarism by asking whether they considered specific practices as plagiarism. We analyzed if respondents in China and Europe responded differently, using logistic regression analysis with adjustments for demographic and other relevant factors.
\end{abstract}

Results: The authors obtained valid responses from 204 researchers based in China (response rate 2.1\%) and 826 researchers based in Europe (response rate 5.6\%). Copying text from someone else's publication without crediting the source, using idea(s) from someone else's publication without crediting the source and republishing one's own work in another language without crediting the source were considered as plagiarism by 98, 67 and 64\%, respectively. About one-third of the respondents reported to have been unsure whether they had been plagiarizing.

Overall, the pattern of responses was similar among respondents based in Europe and China. Nevertheless, for some items significant differences did occur in disadvantage of Chinese respondents.

Conclusions: Findings indicate that nearly all biomedical researchers understand (and disapprove of) the most obvious forms of plagiarism, but uncertainties and doubts were apparent for many aspects. And the minority of researchers who did not recognize some types of plagiarism as plagiarism was larger among China-based respondents than among Europe-based respondents. The authors conclude that biomedical researchers need clearer working definitions of plagiarism in order to deal with grey zones.

Keywords: Plagiarism, Research misconduct, Biomedicine, University researchers, Europe, China

\footnotetext{
*Correspondence: nina.yi@hotmail.com

'Department of Medical Humanities, School of Humanities, Southeast University, Nanjing 211189, China

${ }^{2}$ Centre for Biomedical Ethics and Law, Department of Public Health and Primary Care, KU Leuven, Leuven, Belgium

Full list of author information is available at the end of the article
}

(c) The Author(s). 2020 Open Access This article is licensed under a Creative Commons Attribution 4.0 International License, which permits use, sharing, adaptation, distribution and reproduction in any medium or format, as long as you give appropriate credit to the original author(s) and the source, provide a link to the Creative Commons licence, and indicate if changes were made. The images or other third party material in this article are included in the article's Creative Commons licence, unless indicated otherwise in a credit line to the material. If material is not included in the article's Creative Commons licence and your intended use is not permitted by statutory regulation or exceeds the permitted use, you will need to obtain permission directly from the copyright holder. To view a copy of this licence, visit http://creativecommons.org/licenses/by/4.0/. The Creative Commons Public Domain Dedication waiver (http://creativecommons.org/publicdomain/zero/1.0/) applies to the data made available in this article, unless otherwise stated in a credit line to the data. 


\section{Background}

Integrity has been regarded as the foundation of scientific research $[1,2]$. Unfortunately, research is sometimes conducted with violations of integrity [3-6]. Despite differences among various definitions of research misconduct, fabrication, falsification and plagiarism (FFP) are always included as severe deviations [7-9].

Unlike data fabrication and falsification, which are easily understood and universally viewed as reprehensible, plagiarism is more complex, both in theory and in practice, and it is, therefore, likely to be perceived variably by people, including scientists. The notion of plagiarism arose after the Renaissance, when in many fields individual intellectual work became more valued than before [10]. Henceforth, authors could be accused of plagiarism if they failed to give due credit to their predecessors. After hundreds of years, agreement emerged on how to define plagiarism: taking work (including words, images or ideas) from others without proper reference [11-13]. Nevertheless, although plagiarism seems to be thoroughly defined, experience suggests that grey zones of plagiarism remain.

It has been posited that people from different cultures have different understandings of what constitutes plagiarism [14-16]. Some scholars attributed the existence of divergences to differences in history, education and other factors between Western and other cultures [14, 16-18]. They argued that the notion of plagiarism originated from Western culture, since the time when words and ideas became valued as individual property, which might be perceived differently by other, mainly Asian, cultures $[14,19-21]$. On the other hand, memorization and repetition have been very important in Chinese education and examinations, and students were encouraged to memorize and repeat literally the words of classic Confucian texts and other reputed historical persons, whereas proper citation (according to Western standards of referencing) was not emphasized [20, 22, 23]. With increasing intercultural communication, things have changed, but the influence of cultures cannot be ignored. A few empirical studies also revealed that Chinese scholars/students were not always capable of identifying certain forms of plagiarism [19, 21].

Some surveys and interview studies have investigated the influence of cultural factors on the perception of plagiarism. However, these studies mainly focused on students in universities $[15,16,20,24]$. Since plagiarism is also a common problem among researchers and academics, it is important to test perceptions of plagiarism among scientific researchers of different cultures. Past studies among scientific researchers primarily examined the prevalence of plagiarism and attitudes towards specific forms of plagiarism $[25,26]$, as opposed to the very substance of plagiarism. As a consequence, little is known about the understanding of plagiarism among scientific researchers with different cultural backgrounds.

Considering the vast cultural difference between China and European countries, and the increasingly large number of scientific publications from China [3], the aim of our study was to investigate the understanding of plagiarism among biomedical researchers in Europe and China, and to explore if differences exist in the perception of plagiarism between both regions.

\section{Methods \\ Survey instrument \\ Questionnaire design}

We designed a questionnaire based on the TURNITIN definition of plagiarism [27], our review of documents on scientific integrity in Chinese universities [28] and an interview study of Chinese scholars based in Europe [29]. The survey contained three parts (see Additional file 1). Demographic information, such as age, gender, academic position, having a $\mathrm{PhD}$ degree and international research experience, was collected in the beginning of the questionnaire. The following section (Section 1) included questions regarding respondents' general views about plagiarism, including factors determining their judgment whether an action constitutes plagiarism, and comparing the perceived seriousness of plagiarism with other forms of malpractice. The main section (Section 2) assessed the understanding of plagiarism, where several statements were divided into 7 categories based on their thematic similarity and respondents were asked to select the one(s) they thought constituted plagiarism.

\section{Questionnaire elaboration}

The questionnaire was elaborated using methodology similar to the study of Liao et al. [30]. A first version of the questionnaire was sent to three experts for their review and comments on structure and content. Based on their comments, the questionnaire was modified and then submitted to 14 researchers (philosophers, lawyers, medical doctors, ethicists, pharmacists, psychologists, biomedical scientists; originating from 6 different countries) at the Centre for Biomedical Ethics and Law, KU Leuven, for further refinement.

The original survey was designed in English. Since the survey also targeted Chinese researchers, the questionnaire was translated into Chinese by the first author NY. To validate the language, the translated questionnaire and the original questionnaire were sent for review to three Chinese doctoral and postdoctoral biomedical researchers, who had worked in international research environments. Additional minor changes were made according to their comments. 
Based on the suggestions received from the respondents after the first release of the online survey, we further improved the questionnaire and added the option of "none of the above" for each question in Section 2.

\section{Selection and invitation of respondents}

Our study was targeted at biomedical researchers (i.e. researchers active in medicine, pharmaceutical sciences and life sciences) based at leading research universities in Europe and China. We selected 13 universities from the League of European Research Universities (based on whether they had medical schools and regional spread) $[31,32]$ and 33 universities with biomedical schools from Class A Universities of the Double First Class University in China (see Additional file 2) [33, 34]. The first author (NY) manually retrieved the e-mail addresses of all researchers (professors, associate professors, assistant professors, postdoctoral researchers) whose email addresses were available on the university websites. (Other people, such as doctoral or master students, and administrative staff were also included if their academic position was not clearly indicated on the website, but their academic positions were inquired about by our questionnaire.)

Using her personal KU Leuven e-mail address, the first author NY sent invitation e-mails (with "Invitation to the survey of plagiarism definition" as the subject of the e-mail) (see Additional file 3) explaining the purpose of the study and providing a link to the online questionnaire to all the target researchers (except for the researchers based at KU Leuven, where the invitation was sent by the university). Europe-based researchers received the invitation in English and China-based researchers received the invitation in both English and Chinese. E-mails were sent in bulks grouped by university but without the names of recipients being visible. The anonymity of participation was guaranteed. Reminders were sent after 2 and 4 weeks (except for KU Leuven, where only one reminder was sent by the university after 2 weeks). All data were collected from March 2018 to July 2018.

\section{Ethics, consent and permissions}

The study was approved by the Social and Societal Ethics Committee of the KU Leuven (dossier G- 2017 08885).

Filling out the survey counts as informed consent to participate in this study, which was clearly indicated in the online questionnaire and approved by the Social and Societal Ethics Committee of the KU Leuven.

\section{Statistical methodology}

Summary data are presented as means and standard deviations for continuous variables and as percentages (the number of respondents selecting each option/the total number of valid responses $\times 100$ ) for categorical variables.

In general, the null hypotheses were that the proportions of responses to the questions would not differ between the groups of European and Chinese respondents.

Comparisons of percentages between the European and Chinese universities were performed using the Chi square test for binary variables and categorical variables (gender, mother tongue, current academic position, $\mathrm{PhD}$ degree, year of obtaining $\mathrm{PhD}$ degree (in 10-year categories) and international research experience) or Mann-Whitney U test for continuous variables (age). Logistic regression models and proportional odds models were used to compare Europe-based and China-based respondents for binary variables and ordinal variables, correcting for demographic differences. These models were also used to analyze the association of demographic factors with responses to the other questions. Values of odds ratios (ORs) and their 95\% confidence intervals (CIs) were calculated. The null hypothesis was rejected when a two-tailed $P$ value was less than 0.05 . For three demographic factors: gender, current academic position and year of $\mathrm{PhD}$, the two other factors were corrected when analyzing the association of one factor with the responses to questions in Section 1 and 2.

For questions of Section 2 in each group (see Additional file 1), the kappa coefficient was determined as a measure of consistency within each respondent between the responses to different questions.

Data Analyses were performed using SAS 9.4.

Reporting of this study follows the STROBE statement [35].

\section{Results}

For the first round of surveys, we sent e-mails to 25,648 biomedical researchers based at leading universities in China and Europe, and 1397 emails were bounced back. These addresses to which emails were not delivered successfully were regarded as invalid addresses. For the second and the third round, we sent reminder emails to the other 24,251 valid addresses and eventually collected valid responses from 1030 respondents (total response rate 4.2\%), 826/14,757 (5.6\%) from Europe and 204/9494 (2.1\%) from China. The numbers of respondents who answered some questions about demographic characteristics do not add up to 1030 because some invalid answers were excluded. Only complete responses and responses with fewer than two invalid answers were included, and analyzed as valid responses. The exact numbers are shown in Table 1 and Table 2 .

\section{Demographic information}

Table 1 displays demographic and academic characteristics of the respondents. The values of mean and 
Table 1 Demographic characteristics of the respondents

\begin{tabular}{|c|c|c|c|c|}
\hline Variables & $\begin{array}{l}\text { Percentage of total respondents } \\
(\%)\end{array}$ & $\begin{array}{l}\text { Percentage of researchers in Europe } \\
\text { (\%) }\end{array}$ & $\begin{array}{l}\text { Percentage of researchers in China } \\
(\%)\end{array}$ & $\begin{array}{l}P \\
\text { value }^{a}\end{array}$ \\
\hline \multicolumn{5}{|l|}{ Age $(n=1026)$} \\
\hline$<=30 y$ & 10.3 & 11.0 & 7.4 & \multirow[t]{5}{*}{$<.001$} \\
\hline $31-40 y$ & 33.7 & 32.3 & 39.6 & \\
\hline $41-50 y$ & 24.7 & 22.3 & 34.1 & \\
\hline $51-60 y$ & 20.6 & 21.6 & 16.3 & \\
\hline$>60 y$ & 10.7 & 12.7 & 2.5 & \\
\hline \multicolumn{5}{|l|}{ Gender $(n=1029)$} \\
\hline Female & 41.6 & 44.6 & 29.4 & \multirow[t]{2}{*}{$<.001$} \\
\hline Male & 58.4 & 55.4 & 70.6 & \\
\hline \multicolumn{5}{|l|}{ Mother tongue $(n=1030)$} \\
\hline Chinese & 21.3 & 2.7 & 96.6 & \multirow[t]{3}{*}{$<.001$} \\
\hline English & 13.3 & 16.1 & 2.0 & \\
\hline Other & 65.4 & 81.2 & 1.5 & \\
\hline \multicolumn{5}{|c|}{ Current academic position $(n=1030)$} \\
\hline Professor & 29.7 & 25.2 & 48.0 & \multirow[t]{6}{*}{$<.001$} \\
\hline Associate professor & 21.6 & 19.2 & 30.9 & \\
\hline Assistant professor & 9.8 & 10.6 & 6.4 & \\
\hline Postdoc & 20.4 & 24.5 & 3.9 & \\
\hline Other & 16.3 & 18.5 & 7.4 & \\
\hline $\begin{array}{l}\text { Not a scientific } \\
\text { researcher }\end{array}$ & 2.2 & 1.9 & 3.4 & \\
\hline \multicolumn{5}{|l|}{ PhD degree $(n=1030)$} \\
\hline Yes & 84.3 & 82.6 & 91.2 & \multirow[t]{3}{*}{0.001} \\
\hline Current PhD candidate & 7.4 & 8.8 & 1.5 & \\
\hline No & 8.4 & 8.6 & 7.4 & \\
\hline \multicolumn{5}{|c|}{ Year of obtaining PhD degree $(n=828)$} \\
\hline$<1979$ & 2.3 & 2.9 & 0.0 & \multirow[t]{5}{*}{$<.001$} \\
\hline 1979-1988 & 6.4 & 7.5 & 2.3 & \\
\hline 1989-1998 & 19.4 & 22.0 & 9.8 & \\
\hline 1999-2008 & 33.0 & 28.3 & 50.6 & \\
\hline 2009-2018 & 38.9 & 39.3 & 37.4 & \\
\hline \multicolumn{5}{|c|}{ International research experience ( $>6$ months) $(n=1030)$} \\
\hline Yes & 62.4 & 62.1 & 63.7 & \multirow[t]{2}{*}{0.669} \\
\hline No & 37.6 & 37.9 & 36.3 & \\
\hline
\end{tabular}

${ }^{a} P$ values based on Chi square tests when comparing Europe and China

standard deviation for age (in years) of respondents in Europe and China were $45.2 \pm 12.3$ and $42.6 \pm 8.6$, respectively. The majority of respondents were aged 3160 years, with the proportion of this age category being larger in China. There were more male respondents (58.4\%), with a higher proportion in China (70.6\%). A minority of respondents had English as their mother tongue (16\% in Europe and 2\% in China).

The respondents were mainly professors $(29.7 \%)$ and associate professors (21.6\%). More than $80 \%$ of the respondents had a $\mathrm{PhD}$ degree, typically obtained since 1999 (71.9\%). More than 60\% of the respondents in both regions had international research experience of more than 6 months, with no difference between Europe and China.

In view of the demographic differences between respondents from Europe and China, we conducted all logistic regression analyses with adjustments for those variables (including age, gender, academic position, $\mathrm{PhD}$ and international research experience) to yield adjusted 
Table 2 Percentage of respondents who regarded the practice as plagiarism

\begin{tabular}{|c|c|c|c|c|c|}
\hline Statement of practice & $\begin{array}{l}\text { Percentage of total } \\
\text { respondents (\%, } \\
n=1030)\end{array}$ & $\begin{array}{l}\text { Percentage of } \\
\text { researchers in } \\
\text { Europe }(\%, n=826)\end{array}$ & $\begin{array}{l}\text { Percentage of } \\
\text { researchers in China } \\
(\%, n=204)\end{array}$ & $\begin{array}{l}P \\
\text { value }^{a}\end{array}$ & $\begin{array}{l}\text { Adjusted } \\
\text { OR }(95 \% \\
\text { CI) }\end{array}$ \\
\hline \multicolumn{6}{|l|}{ Statement 17. Appropriation of others' text, image and ideas } \\
\hline $\begin{array}{l}\text { a. Copying text from someone else's publication without } \\
\text { crediting the source. }\end{array}$ & 97.7 & 98.7 & 93.6 & $<.001$ & $\begin{array}{l}0.15 \\
(0.05 \\
0.43)\end{array}$ \\
\hline $\begin{array}{l}\text { b. Copying text from someone else's publication with } \\
\text { crediting the source, but without quotation marks. }\end{array}$ & 48.5 & 51.6 & 36.3 & $<.001$ & $\begin{array}{l}0.40 \\
(0.27 \\
0.59)\end{array}$ \\
\hline $\begin{array}{l}\text { c. Copying text from someone else's publication with } \\
\text { crediting the source and with quotation marks. }\end{array}$ & 6.1 & 6.2 & 5.9 & 0.876 & $\begin{array}{l}1.09(0.51 ; \\
2.36)\end{array}$ \\
\hline $\begin{array}{l}\text { d. Copying an image from someone else's publication } \\
\text { without crediting the source. }\end{array}$ & 96.0 & 96.4 & 94.6 & 0.249 & $\begin{array}{l}0.54(0.22 ; \\
1.34)\end{array}$ \\
\hline $\begin{array}{l}\text { e. Using idea(s) from someone else's publication without } \\
\text { crediting the source. }\end{array}$ & 67.1 & 67.4 & 65.7 & 0.634 & $\begin{array}{l}1.03(0.70 ; \\
1.53)\end{array}$ \\
\hline \multicolumn{6}{|l|}{ Statement 18. Appropriation of online sources } \\
\hline $\begin{array}{l}\text { a. Copying text from an online source without crediting the } \\
\text { source. }\end{array}$ & 95.5 & 97.3 & 88.2 & $<.001$ & $\begin{array}{l}0.20 \\
(0.09 \\
0.45)\end{array}$ \\
\hline $\begin{array}{l}\text { b. Copying text from an online source that has no list of } \\
\text { authors, and without crediting the source. }\end{array}$ & 79.2 & 81.7 & 69.1 & $<.001$ & $\begin{array}{l}0.46 \\
(0.30 \\
0.71)\end{array}$ \\
\hline \multicolumn{6}{|l|}{ Statement 19. Rephrasing or summarizing another person's work } \\
\hline $\begin{array}{l}\text { a. Rephrasing another person's work without crediting the } \\
\text { source. }\end{array}$ & 84.6 & 83.8 & 87.8 & 0.160 & $\begin{array}{l}1.27(0.75 ; \\
2.17)\end{array}$ \\
\hline $\begin{array}{l}\text { b. Rephrasing text from someone else's publication without } \\
\text { significant modification of the original, but with crediting } \\
\text { the source. }\end{array}$ & 16.9 & 17.7 & 13.7 & 0.178 & $\begin{array}{l}0.77(0.46 ; \\
1.29)\end{array}$ \\
\hline $\begin{array}{l}\text { c. Summarizing another person's work without crediting the } \\
\text { source. }\end{array}$ & 78.6 & 80.5 & 71.1 & 0.003 & $\begin{array}{l}0.68(0.44 ; \\
1.04)\end{array}$ \\
\hline \multicolumn{6}{|l|}{ Statement 20. Text resources of article writing } \\
\hline $\begin{array}{l}\text { a. Paying someone else to write a paper without granting } \\
\text { authorship. }\end{array}$ & 37.3 & 33.5 & 52.4 & $<.001$ & $\begin{array}{l}2.44 \\
(1.67 \\
3.55)\end{array}$ \\
\hline $\begin{array}{l}\text { b. Having someone else to write a paper for free without } \\
\text { granting authorship. }\end{array}$ & 49.5 & 46.0 & 63.7 & $<.001$ & $\begin{array}{l}2.18 \\
(1.50 \\
3.17)\end{array}$ \\
\hline $\begin{array}{l}\text { c. Putting together pieces from different publications, and } \\
\text { presenting the result as one's own work. }\end{array}$ & 94.4 & 95.0 & 91.7 & 0.062 & $\begin{array}{l}0.50(0.24 ; \\
1.04)\end{array}$ \\
\hline $\begin{array}{l}\text { d. When writing a literature review, using the same } \\
\text { framework of others' review, without crediting the source. }\end{array}$ & 53.1 & 53.0 & 53.4 & 0.917 & $\begin{array}{l}1.01(0.70 ; \\
1.45)\end{array}$ \\
\hline $\begin{array}{l}\text { e. With permission from the original author, using another's } \\
\text { text without crediting the source. }\end{array}$ & 67.4 & 68.9 & 61.3 & 0.038 & $\begin{array}{l}0.65 \\
(0.44 ; \\
0.96)\end{array}$ \\
\hline \multicolumn{6}{|l|}{ Statement 21. Publishing in multiple languages } \\
\hline $\begin{array}{l}\text { a. Republishing others' work in another language without } \\
\text { crediting the source. }\end{array}$ & 98.4 & 98.4 & 98.5 & 0.915 & $\begin{array}{l}1.47(0.34 ; \\
6.38)\end{array}$ \\
\hline $\begin{array}{l}\text { b. Republishing one's own work in another language } \\
\text { without crediting the source. }\end{array}$ & 64.2 & 67.7 & 50.00 & $<.001$ & $\begin{array}{l}0.38 \\
(0.26 \\
0.56)\end{array}$ \\
\hline \multicolumn{6}{|l|}{ Statement 22. Reuse of research proposal } \\
\hline $\begin{array}{l}\text { a. Reusing one's own previously rejected research proposal } \\
\text { for another funding application without crediting the } \\
\text { source. }\end{array}$ & 11.2 & 9.3 & 18.6 & $<.001$ & $\begin{array}{l}2.17 \\
(1.27 \\
3.70)\end{array}$ \\
\hline b. Reusing a significant portion of one's own previous & 79.0 & 79.4 & 77.4 & 0.536 & $0.65(0.41 ;$ \\
\hline
\end{tabular}


Table 2 Percentage of respondents who regarded the practice as plagiarism (Continued)

\begin{tabular}{|c|c|c|c|c|c|}
\hline Statement of practice & $\begin{array}{l}\text { Percentage of total } \\
\text { respondents }(\%, \\
n=1030)\end{array}$ & $\begin{array}{l}\text { Percentage of } \\
\text { researchers in } \\
\text { Europe }(\%, n=826)\end{array}$ & $\begin{array}{l}\text { Percentage of } \\
\text { researchers in China } \\
(\%, n=204)\end{array}$ & $\begin{array}{l}P \\
\text { value }^{\mathrm{a}}\end{array}$ & $\begin{array}{l}\text { Adjusted } \\
\text { OR }(95 \% \\
\text { Cl) })^{\mathrm{b}}\end{array}$ \\
\hline $\begin{array}{l}\text { publication for a new publication without crediting the } \\
\text { source. }\end{array}$ & & & & & 1.01) \\
\hline \multicolumn{6}{|l|}{ Statement 23. Republication of dissertations } \\
\hline $\begin{array}{l}\text { a. One has submitted work as dissertation/thesis, and } \\
\text { submits parts of it to a journal afterwards without crediting } \\
\text { the source. }\end{array}$ & 29.2 & 32.4 & 16.2 & $<.001$ & $\begin{array}{l}0.44 \\
(0.28 \\
0.70)\end{array}$ \\
\hline $\begin{array}{l}\text { b. One has submitted work as dissertation/thesis, and } \\
\text { submits a summary of it to a journal afterwards without } \\
\text { crediting the source. }\end{array}$ & 26.3 & 29.5 & 13.2 & $<.001$ & $\begin{array}{l}0.43 \\
(0.26 \\
0.70)\end{array}$ \\
\hline
\end{tabular}

* $P$ values based on Chi square tests when comparing Europe and China

** ORs (with 95\% Cls) based on logistic regression analysis, with adjustments for demographic variables (including age, gender, academic position, PhD,

international research experience). Reference is Europe

odds ratios (aORs) with 95\% confidence intervals (CIs), always taking Europe-based respondents as the reference category.

\section{Perceptions of plagiarism practice}

The majority of respondents from both regions successfully identified most statements of plagiarism (Table 2). Nevertheless, in several instances the likelihood of not perceiving some practices as plagiarism did differ significantly between respondents in Europe and China. Most odds ratios were not materially affected by adjusting for demographic variables, except for one statement (summarizing another person's work without crediting the source) for which significance between European and Chinese respondents disappeared after adjustment.

Almost all respondents in both Europe (98.7\%) and China (93.6\%) considered copying text without crediting the source as plagiarism. Nevertheless, the minority of respondents who did not successfully recognize this most obvious form of plagiarism was considerably larger (five-fold) for respondents from China (6.4\%) than for respondents from Europe (1.3\%), thus yielding a highly significant aOR of 0.15 (95\%CI 0.05;0.43) (Europe being taken as the reference). For copying images, the difference between China (5.4\%) and Europe (4.6\%) did not reach significance (aOR 0.54, 95\% CI 0.22;1.34). Using someone else's ideas without giving credit was considered as plagiarism by two thirds (67\%) of respondents, again without difference between China and Europe (aOR 1.03, 95\% CI 0.70:1.53). Copying text with crediting the source, without quotation marks was regarded as plagiarism by half of the total respondents, with China-based respondents being less likely to do so (aOR 0.40, 95\%CI 0.27;0.59).

Compared to copying text, respondents were generally more lenient about improper rephrasing, especially close rephrasing. Rephrasing another person's work without crediting the source and summarizing another person's work without crediting the source were perceived as plagiarism by around four fifths of the respondents, without differences between China-based and Europe-based respondents (after adjustment for demographic characteristics). In contrast, almost one fifth of the respondents indicated rephrasing text from someone else's publication without significant modification of the original, but with crediting the source as plagiarism.

With respect to online sources, the majority (96\%) of the respondents reported copying from an online source without crediting the source as plagiarism, while fewer (79\%) reported copying from an online source with no list of authors, and without crediting the source as plagiarism. In contrast to respondents in Europe (97.3 and $81.7 \%$, respectively), respondents in China (88.2 and 69.1\%, respectively) were significantly less likely to consider these practices as plagiarism, yielding aORs of 0.20 and 0.46 , respectively.

Perceptions about resources of article writing were examined as well. A substantial number of respondents did report that having someone else write a paper constituted plagiarism, but it depended on the payment: almost half of the respondents indicated that having someone else to write a paper for free without granting authorship was plagiarism, while fewer (37\%) indicated that paying someone else to write a paper without granting authorship constituted plagiarism. In addition to these two practices, nearly one third of the respondents did not consider using another's text without crediting the source, but with permission from the original author as plagiarism. Compared to respondents in Europe (34 and 46\%), more respondents in China (52 and 64\%) tended to indicate that paying someone else to write a paper without granting authorship and having someone else to write a paper for free without granting authorship constituted plagiarism, with significant aORs of 2.44 and 2.18.

Publishing in multiple languages was also perceived differently. Almost all respondents indicated republishing 
others' work in another language without crediting the source as plagiarism (98\%), while less than two thirds considered republishing one's own work in another language without crediting the source as plagiarism. In contrast to respondents in Europe (68\%), fewer respondents in China (50\%) tended to identify republishing one's own work in another language without crediting the source as plagiarism, yielding a significant aOR of 0.38 .

\section{General views about plagiarism}

In addition to the specific practices above, we also explored some other aspects of plagiarism.

In general, the respondents indicated that plagiarism was a bigger threat to biomedical research than granting co-authorship to someone whose contribution doesn't justify it and submitting a manuscript to more than one journal simultaneously, but a lesser threat than data falsification (Fig. $1 \mathrm{a}-\mathrm{c}$ ). Compared to their counterparts in Europe, the respondents in China showed a stricter attitude.

Respondents' other views about plagiarism are presented in Table 3. Perceived factors that determine whether a body of copied and unattributed text constitutes plagiarism were inquired in the survey. About $6 \%$ of the respondents reported that the practice of plagiarism did not depend on the intention, the length or the part of the copied text. In contrast, three-quarter of the respondents $(75 \%)$ indicated that intention should be considered when deciding whether a practice is plagiarism or not. Half of the respondents indicated that the length (53\%) and the part (45\%) of the copied text did matter. In contrast to respondents in Europe, those in China tended to agree more frequently ( $55 \%$ vs $43 \%$, aOR 1.91) that part of the copied text determined whether a practice was plagiarism or not $(p<0.05)$. On the contrary, compared to respondents in Europe (77\%), those in China (67\%) tended to agree less frequently that the intention mattered (aOR 0.59).

At the practical level, nearly one third of the respondents stated to have been unsure whether they had been plagiarizing. Compared with respondents in Europe (34\%), respondents in China (18\%) were significantly less likely to doubt whether they had been plagiarizing ( $\mathrm{aOR}$ 0.41).

\section{Association with demographic factors}

The responses to some questions were associated with some demographic factors, such as age, gender, mother tongue and (year of) $\mathrm{PhD}$ degree (Table 4), which justified the necessity of correction for these factors when comparing responses in China and Europe (as presented in Table 2 and Table 3).
More specifically, responses to many questions differed with the mother tongue. For example, compared with the other language (neither English-native nor Chinesenative) speakers, Chinese-native speakers were more likely to agree that plagiarism was a greater threat to biomedical research than the other given malpractices - data falsification, gift authorship and multiple submission - but they were less sensitive to plagiarism of online sources. They were also less likely to perceive that the intention decided whether or not a body of copied and unattributed text constitutes plagiarism.

Moreover, other factors also had effects on the responses. As age increased, participants were less likely to doubt whether they themselves had committed plagiarism. Researchers without a $\mathrm{PhD}$ degree were more likely to doubt whether they themselves had been plagiarizing. Researchers without a $\mathrm{PhD}$ degree (not a $\mathrm{PhD}$ candidate, either) had more concerns with republication of dissertations and misuse of one's previously research proposals and less sensitivity towards copying an image from someone else's publication without crediting the source and reusing a significant portion of one's own previous publication for a new publication without crediting the source.

Current academic position and year of obtaining $\mathrm{PhD}$ proved to associate with understanding of a few practices as well.

\section{Agreement analysis}

Agreement analysis was performed for questions in the same group in Section 2 to explore the consistency within each respondent between perceptions of different practices. Despite the little internal consistency among the responses to most practices, we did observe agreement between a few practices, as follows (More data is available in Additional file 4). Respondents who considered paying someone else to write a paper without granting authorship as plagiarism, also tended to consider having someone else to write a paper for free without granting authorship as plagiarism (Kappa coefficient $=0.71$ ).

Regarding republication of a dissertation/thesis, respondents who indicated one has submitted work as dissertation/thesis, and submits parts of it to a journal afterwards without crediting the source as plagiarism, also tended to indicate one has submitted work as dissertation/thesis, and submits a summary of it to a journal afterwards without crediting the source as plagiarism (Kappa coefficient $=0.78$ ).

\section{Discussion}

Plagiarism has been consistently regarded as a severe type of research misconduct, on a par with fabrication and falsification [10-12]. Many scholars have discussed 
(a)

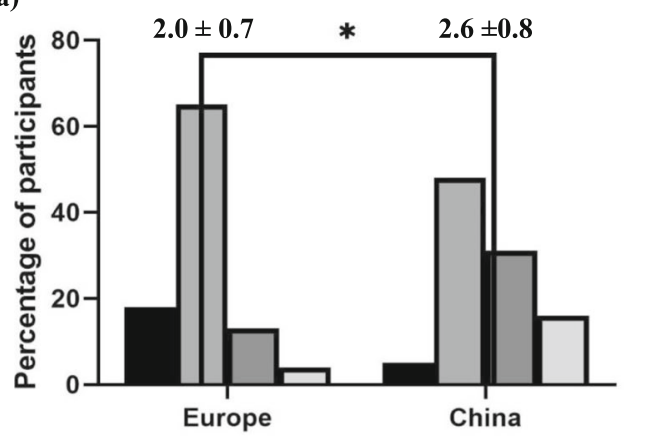

- Strongly disagree

ㅁ Disagree

ㅁ Agree

Strongly agree

(b)

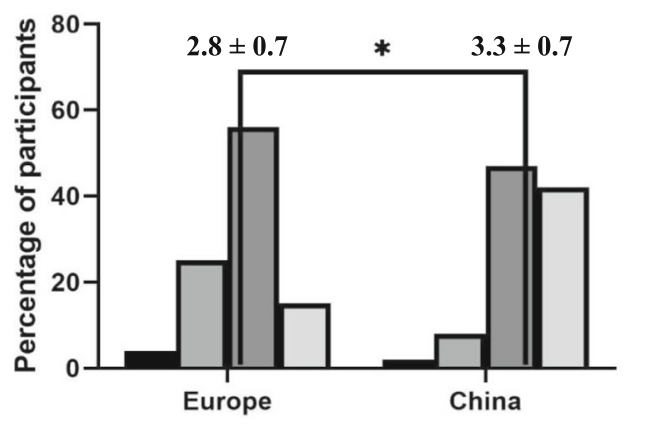

Strongly disagree
Disagree
$\square$ Agree
$\square$ Strongly agree

(c)

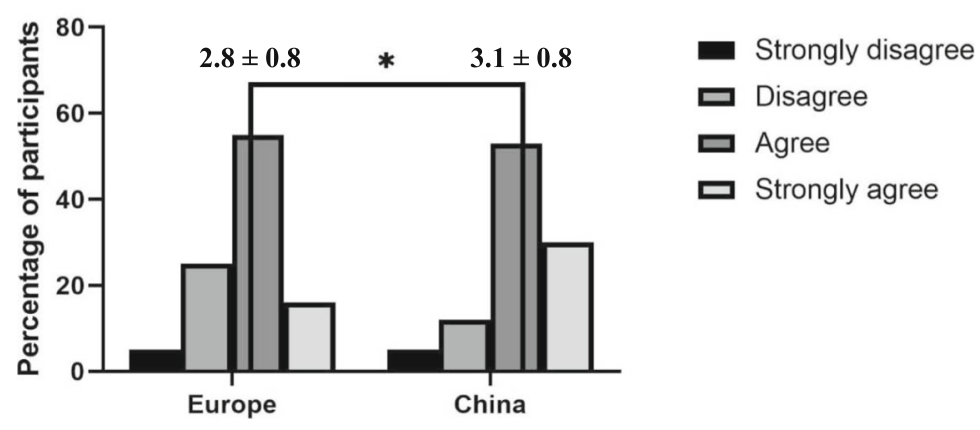

Fig. 1 a Attitudes towards the statement "Plagiarism is a greater threat to biomedical research than data falsification". ${ }^{*} P<0.001($ MannWhitney test); Strongly disagree $=1$, Disagree $=2$, Agree $=3$, Strongly agree $=4$; Means and standard deviations (SD) of the scores are presented as: mean \pm SD. $\mathbf{b}$ Attitudes towards the statement "Plagiarism is a greater threat to biomedical research than granting co-authorship to someone whose contribution doesn't justify it". * $P<0.001$ (Mann-Whitney test); Strongly disagree $=1$, Disagree $=2$, Agree $=3$, Strongly agree $=4$; Means and standard deviations (SD) of the scores were presented as: mean \pm SD. $\mathbf{c}$ Attitudes towards the statement "Plagiarism is a greater threat to biomedical research than submitting a manuscript to more than one journals simultaneously". * $P<0.001$; Strongly disagree $=1$, Disagree $=2$, Agree $=3$, Strongly agree $=4$; Means and standard deviations (SD of the scores were presented as: $m e a n \pm S D$

the nature and harm of plagiarism, such as violation of integrity, intellectual property, infringement of the copyright, monetary loss of others [36-38]. Definitions, reasons, prevalence of and attitudes towards plagiarism have also been studied [21, 39-43]. However, when we discuss and address plagiarism worldwide, one question appears to have been somehow ignored: How do scientists understand plagiarism? The present study aimed to provide some insights into this question. Through an online survey, we investigated if biomedical researchers in Europe and China differed in their perceptions of certain practices as plagiarism. Our findings revealed a range of perceptions of plagiarism in both Europe and China. In terms of prevalences of answers to most of the questions on plagiarism, the differences between Chinabased and Europe-based respondents were not impressive, indicating that the knowledge and perception about plagiarism were largely similar in the two groups. Nevertheless, when looking at adjusted ORs, the likelihood of perceiving things differently proved substantial for some 
Table 3 Percentage of respondents who selected each option

\begin{tabular}{|c|c|c|c|c|c|}
\hline Question & $\begin{array}{l}\text { Percentage of total } \\
\text { respondents }(\%, n=1030)\end{array}$ & $\begin{array}{l}\text { Percentage of researchers in } \\
\text { Europe }(\%, n=826)\end{array}$ & $\begin{array}{l}\text { Percentage of researchers } \\
\text { in China }(\%, n=204)\end{array}$ & value $^{*}$ & $\begin{array}{l}\text { Adjusted OR } \\
\left(95 \% \mathrm{Cl}^{* *}\right.\end{array}$ \\
\hline \multicolumn{6}{|c|}{ Question 15. Which factor(s) do you think decides whether a body of copied and unattributed text constitutes plagiarism or not? } \\
\hline a. The length of the copied text & 53.0 & 51.3 & 59.8 & 0.030 & $\begin{array}{l}1.24(0.86 \\
1.80)\end{array}$ \\
\hline b. The part of the copied text & 45.2 & 42.6 & 55.4 & 0.001 & $\begin{array}{l}1.91(1.32, \\
2.77)\end{array}$ \\
\hline $\begin{array}{l}\text { c. The presence of an intention to } \\
\text { copy without attribution }\end{array}$ & 75.3 & 77.4 & 67.2 & 0.002 & $\begin{array}{l}0.59(0.39, \\
0.89)\end{array}$ \\
\hline \multicolumn{6}{|c|}{ Question 16. Have you ever been unsure whether you are plagiarizing? } \\
\hline a. Yes & 31.3 & 34.5 & 18.1 & $<.001$ & $\begin{array}{l}0.41(0.26 \\
0.64)\end{array}$ \\
\hline
\end{tabular}

a $P$ values based on Chi square tests when comparing Europe and China

b ORs (with 95\% Cls) based on logistic regression analysis, with adjustment for demographic variables (including age, gender, academic position, PhD, international research experience). Reference is Europe

practices. In other words, the minority of respondents with a "deviant" response proved substantially larger among China-based respondents compared to Europebased respondents in some instances. The findings also suggest that despite a good understanding of plagiarism by most respondents, knowledge of plagiarism is still lacking among some respondents, especially regarding certain subtle forms of plagiarism.

\section{Differences between respondents in Europe and China}

Respondents in China were significantly less likely than respondents in Europe to consider the following five practices as plagiarism, even though four of these practices are regarded as plagiarism by internationally agreed guidance or policy $[11,12]$ : copying unattributed text from someone else's publication (aOR 0.15); copying attributed text from someone else's publication, but without quotation marks (aOR 0.40); copying text from an online source without crediting the source (aOR 0.20); copying text from an online source that has no list of authors, and without crediting the source (aOR 0.46) and submitting parts of or a summary of one's previous thesis (aOR 0.44 and 0.43 , respectively). To our knowledge, republishing from one's thesis is not always treated as plagiarism, but the differences between respondents in both regions might reflect the divergently rigorous and prudent attitudes in scientific publishing.

Republishing one's own work in another language without referencing was also less likely to be perceived as plagiarism by respondents in China (aOR 0.38). Of note, one third of Europe-based researchers in our survey also did not view this practice as plagiarism. Yet, unacknowledged duplicate publication in another language is deemed as self-plagiarism or duplicate (dual) publication $[8,44,45]$, which is unequivocally an undesirable practice. Some Chinese scholars republish their work in English after successfully publishing the same work in Chinese, so as to gain more publications and increase their competitiveness in promotion [46]. In their empirical analysis, Tucker et al. [47] also observed substantial overlap with Chinese published work in around one fifth of the English manuscripts from Chinese institutions. In this regard, it is not surprising, according to our findings, that only half of the respondents in China considered duplicate republication in another language as plagiarism. This agrees with the survey of Pupovac et al., where about half of the students surveyed found that self-plagiarism was "harmless" or "justified" [43].

On the contrary, paid or unpaid ghostwriting was regarded as plagiarism by more respondents in China than in Europe (aOR 2.44 and 2.18, respectively). As noted by previous reports, ghostwriting and online ghostwriting transactions are not rare in China $[46,48]$, especially among medical researchers, including doctors, whose promotion relies on publication of SCI papers rather than on the number of patients they see [46]. We speculate that Chinese scholars in our sample were more likely than European scholars to consider ghostwriting as objectionable, because they were more exposed not only to ghostwriting and ghostwriting transactions, but also to negative reports about the practice.

Surprisingly, on the one hand, respondents in China were more likely than respondents in Europe to agree that plagiarism was a greater threat to biomedical research than the other three misbehaviors listed in the questionnaire and they also appeared more selfconfident in terms of the understanding of plagiarism. However, on the other hand, they were less likely to detect a few specific practices as plagiarism. This indicates that, in general, respondents in China did realize that plagiarism was unacceptable, but the awareness of what constitutes plagiarism was poor in a larger proportion of respondents. Our findings differ from a recent study by Li et al. [49], which observed a higher acceptance of plagiarism among Chinese scientific researchers. The discrepancy with the latter study may be due to the 
Table 4 Associations with demographic characteristics of all respondents (OR values were presented)

\begin{tabular}{|c|c|c|c|c|c|c|c|}
\hline Question/Statement & $\begin{array}{l}\text { Age } \\
\text { (a) }\end{array}$ & $\begin{array}{l}\text { Gender } \\
\text { (b) }\end{array}$ & $\begin{array}{l}\text { Mother } \\
\text { tongue } \\
\text { (c) }\end{array}$ & $\begin{array}{l}\text { Current } \\
\text { academic } \\
\text { position (d) }\end{array}$ & $\begin{array}{l}\text { PhD } \\
\text { degree } \\
\text { (e) }\end{array}$ & $\begin{array}{l}\text { Year of } \\
\text { PhD } \\
\text { degree }(f)\end{array}$ & $\begin{array}{l}\text { International } \\
\text { research } \\
\text { experience (g) }\end{array}$ \\
\hline Question 12. Greater threat than data falsification & $1.01^{*}$ & $1.44^{*}$ & $\begin{array}{l}4.70(\mathrm{CH}) \\
0.52(\mathrm{E})\end{array}$ & $\sqrt{ }$ & $1.73(\mathrm{~N})$ & & 1.03 \\
\hline Question 13. Greater threat than granting co-authorship & $0.99^{*}$ & 0.77 & $4.65(\mathrm{CH})$ & $\sqrt{ }$ & & $\sqrt{ }$ & 1.08 \\
\hline $\begin{array}{l}\text { Question } 14 . \text { Greater threat than submitting to more than } \\
\text { one journal }\end{array}$ & $0.98^{*}$ & 0.96 & $2.66(\mathrm{CH})$ & & & $\sqrt{ }$ & 0.97 \\
\hline \multicolumn{8}{|l|}{ Question 15. Factors deciding plagiarism } \\
\hline a. length of the copied text & 1.01 & 0.81 & $1.42(\mathrm{CH})$ & & $0.50(\mathrm{CP})$ & & 1.03 \\
\hline b. part of the copied text & 1.01 & 0.87 & $\begin{array}{l}1.68(\mathrm{CH}) \\
0.56(\mathrm{E})\end{array}$ & & & & 1.07 \\
\hline c. intention to copy without attribution & 1.00 & 0.78 & $0.64 \mathrm{CH})$ & & & & 0.88 \\
\hline $\begin{array}{l}\text { Question } 16 . \text { Have been unsure whether oneself is } \\
\text { plagiarizing }\end{array}$ & $0.98^{*}$ & 0.91 & $0.43(\mathrm{CH})$ & & $\begin{array}{l}2.24(\mathrm{CP}) \\
1.88(\mathrm{~N})\end{array}$ & & 1.02 \\
\hline \multicolumn{8}{|l|}{ Statement 17. Appropriation of others' text, image and ideas } \\
\hline $\begin{array}{l}\text { a. Copying text from someone else's publication without } \\
\text { crediting the source. }\end{array}$ & 1.00 & 1.77 & $0.20(\mathrm{CH})$ & & & & 0.59 \\
\hline $\begin{array}{l}\text { b. Copying text from someone else's publication with } \\
\text { crediting the source, but without quotation marks. }\end{array}$ & $0.98^{*}$ & 1.03 & $0.62(\mathrm{CH})$ & & & $\sqrt{ }$ & 0.88 \\
\hline $\begin{array}{l}\text { c. Copying text from someone else's publication with } \\
\text { crediting the source and with quotation marks. }\end{array}$ & 1.00 & 1.03 & & & & & 0.70 \\
\hline $\begin{array}{l}\text { d. Copying an image from someone else's publication } \\
\text { without crediting the source. }\end{array}$ & 0.98 & 2.05 & & & $0.32(\mathrm{~N})$ & & 0.56 \\
\hline $\begin{array}{l}\text { e. Using idea(s) from someone else's publication without } \\
\text { crediting the source. }\end{array}$ & 1.00 & $1.44^{*}$ & & & & & 1.04 \\
\hline \multicolumn{8}{|l|}{ Statement 18. Appropriation of online sources } \\
\hline $\begin{array}{l}\text { a. Copying text from an online source without crediting the } \\
\text { source. }\end{array}$ & 0.99 & 2.03 & $0.24(\mathrm{CH})$ & & & & 1.26 \\
\hline $\begin{array}{l}\text { b. Copying text from an online source that has no list of } \\
\text { authors, and without crediting the source. }\end{array}$ & 1.00 & 0.83 & $\begin{array}{l}0.58(\mathrm{CH}) \\
1.86(\mathrm{E})\end{array}$ & & & & 1.09 \\
\hline \multicolumn{8}{|l|}{ Statement 19. Rephrasing or summarizing another person's work } \\
\hline $\begin{array}{l}\text { a. Rephrasing another person's work without crediting the } \\
\text { source. }\end{array}$ & 1.00 & 1.41 & & & & & 0.96 \\
\hline $\begin{array}{l}\text { b. Rephrasing text from someone else's publication without } \\
\text { significant modification of the original, but with crediting the } \\
\text { source. }\end{array}$ & 1.00 & 1.37 & & & & & 0.99 \\
\hline $\begin{array}{l}\text { c. Summarizing another person's work without crediting the } \\
\text { source. }\end{array}$ & $1.02^{*}$ & $1.55^{*}$ & $0.52(\mathrm{CH})$ & & & & 1.31 \\
\hline \multicolumn{8}{|l|}{ Statement 20. Text resources of article writing } \\
\hline $\begin{array}{l}\text { a. Paying someone else to write a paper without granting } \\
\text { authorship. }\end{array}$ & 0.99 & 0.90 & $2.42(\mathrm{CH})$ & $\sqrt{ }$ & $1.79(\mathrm{CP})$ & & 1.17 \\
\hline $\begin{array}{l}\text { b. Having someone else to write a paper for free without } \\
\text { granting authorship. }\end{array}$ & 0.99 & 1.01 & $2.19(\mathrm{CH})$ & $\sqrt{ }$ & & & 1.08 \\
\hline $\begin{array}{l}\text { c. Putting together pieces from different publications, and } \\
\text { presenting the result as one's own work. }\end{array}$ & $1.03^{*}$ & 1.83 & & & & & 0.63 \\
\hline $\begin{array}{l}\text { d. When writing a literature review, using the same } \\
\text { framework of others' review, without crediting the source. }\end{array}$ & $1.02^{*}$ & 1.24 & $0.60(\mathrm{E})$ & & $0.56(\mathrm{CP})$ & & 0.87 \\
\hline $\begin{array}{l}\text { e. With permission from the original author, using another's } \\
\text { text without crediting the source. }\end{array}$ & 1.01 & 1.25 & $0.70(\mathrm{CH})$ & & & & 0.93 \\
\hline \multicolumn{8}{|l|}{ Statement 21. Publishing in multiple languages } \\
\hline a. Republishing others' work in another language without & 0.99 & 1.98 & & & & & 0.60 \\
\hline
\end{tabular}


Table 4 Associations with demographic characteristics of all respondents (OR values were presented) (Continued)

\begin{tabular}{|c|c|c|c|c|c|c|c|}
\hline Question/Statement & $\begin{array}{l}\text { Age } \\
\text { (a) }\end{array}$ & $\begin{array}{l}\text { Gender } \\
\text { (b) }\end{array}$ & $\begin{array}{l}\text { Mother } \\
\text { tongue } \\
\text { (c) }\end{array}$ & $\begin{array}{l}\text { Current } \\
\text { academic } \\
\text { position (d) }\end{array}$ & $\begin{array}{l}\text { PhD } \\
\text { degree } \\
\text { (e) }\end{array}$ & $\begin{array}{l}\text { Year of } \\
\text { PhD } \\
\text { degree }(f)\end{array}$ & $\begin{array}{l}\text { International } \\
\text { research } \\
\text { experience (g) }\end{array}$ \\
\hline $\begin{array}{l}\text { b. Republishing one's own work in another language without } \\
\text { crediting the source. }\end{array}$ & 1.01 & 0.99 & $0.51(\mathrm{CH})$ & & $0.56(\mathrm{~N})$ & & 0.89 \\
\hline \multicolumn{8}{|l|}{ Statement 22. Reuse of research proposal } \\
\hline $\begin{array}{l}\text { a. Reusing one's own previously rejected research proposal for } \\
\text { another funding application without crediting the source. }\end{array}$ & 0.99 & 0.94 & $\begin{array}{l}2.21(\mathrm{CH}) \\
0.34(\mathrm{E})\end{array}$ & & $2.08(\mathrm{~N})$ & $\sqrt{ }$ & 1.08 \\
\hline $\begin{array}{l}\text { b. Reusing a significant portion of one's own previous } \\
\text { publication for a new publication without crediting the } \\
\text { source. }\end{array}$ & 1.00 & $1.54^{*}$ & & & $0.60(\mathrm{~N})$ & & 0.82 \\
\hline \multicolumn{8}{|l|}{ Statement 23. Republication of dissertations } \\
\hline $\begin{array}{l}\text { a. One has submitted work as dissertation/thesis, and submits } \\
\text { parts of it to a journal afterwards without crediting the } \\
\text { source. }\end{array}$ & 1.00 & 1.07 & $\begin{array}{l}0.50(\mathrm{CH}) \\
0.58(\mathrm{E})\end{array}$ & & $1.71(\mathrm{~N})$ & & 1.22 \\
\hline $\begin{array}{l}\text { b. One has submitted work as dissertation/thesis, and submits } \\
\text { a summary of it to a journal afterwards without crediting the } \\
\text { source. }\end{array}$ & 1.01 & 1.20 & $\begin{array}{l}0.38(\mathrm{CH}) \\
0.62(\mathrm{E})\end{array}$ & & $1.92(\mathrm{~N})$ & & $1.35^{*}$ \\
\hline
\end{tabular}

(a)(b) * There is association between the response and the demographic factor

(b) "Male" as the reference

(c) "Other" as the reference. " $\mathrm{CH}$ " stands for Chinese, and "E" stands for English. Only odds ratios with statistical significance are listed

(d) (f) " $\sqrt{ }$ " indicates association between responses to the statement/question and the demographic factor

(e) "PhD" as the reference. "CP" stands for "currently a PhD candidate", and "N" stands for having no PhD degree. Only odds ratios with statistical significance are listed

(g) "With international research experience of more than 6 months" as the reference

different academic domains and different institutions of the respondents in these two studies.

Nevertheless, we cannot conclude (nor exclude) from our survey that "cultural differences" between Chinese and western societies play a role in how plagiarism is perceived by Europe-based and China-based researchers. To further investigate the cultural influence, a more profound "anthropological" approach would be needed in future studies.

In addition to the differences above, the similarities of "correct/incorrect" responses to other questions in both regions are also worth noting.

\section{Perceptions of specific practices "Copying and pasting text" and related practices}

As expected, "copying and pasting text without crediting the source" was perceived as plagiarism by the vast majority of respondents. Nevertheless, in the views of some respondents, certain conditions protected the practice of copying from being plagiarism: copying text from someone else's publication with crediting the source, but without quotation marks; using another's text without crediting the source, but with permission from the original author and rephrasing text from someone else's publication without significant modification of the original, but with crediting the source. Without proper referencing, readers would regard the copied material as original text of the new author(s), which should be deemed as plagiarism [50]. Moreover, paraphrasing without giving credit has been considered undesired by many scholars [51-53]. Compared with simple "copying and pasting", it is more difficult to detect this type of plagiarism with text-matching software and other strategies have to be used. Hence, proper citations, and quotations in some cases, are needed to indicate the origin of the text.

In addition, although most of the surveyed scientists considered copying text without crediting the source as plagiarism, the perception changed with regard to citing from online sources. Fewer respondents considered improper referencing of online sources in the absence of identifiable authors as plagiarism. Other studies have made similar observations. In a survey in 2011, not all university instructors surveyed identified copying texts or images from online sources and close paraphrasing as "definitely plagiarism" [54]. When the definition of plagiarism is not clear to instructors, students in universities are very unlikely to gain correct understanding of plagiarism.

\section{Other practices}

Compared to the practices above, our study discovered no better understanding of other relevant behaviors, such as plagiarism of ideas.

Appropriation of idea(s) without crediting the source, which is clearly defined as plagiarism $[8,12,13]$, was not identified as plagiarism by a substantial minority (33\%) of the respondents. This finding demonstrates that not all respondents had correct and adequate knowledge of basic definitions of plagiarism. Some previous studies 
stated that the value and protection of ideas differed across cultures and that protection of ideas was lacking in Asian countries, including China, where harmony and conformity were valued more than uniqueness [55]. However, our results did not observe this difference between Western and Asian cultures with regard to plagiarism of ideas. More in-depth investigation of this, admittedly, not straightforward issue of plagiarism of ideas might show different results.

\section{Other views}

In general, most respondents considered plagiarism to be more threatening to biomedical research than gift authorship and multiple submission, and less threatening than data falsification. This finding is consistent with the study of Roberts et al. [56], where plagiarism was ranked between data fabrication and inappropriate authorship in terms of severity. One possible reason might be that plagiarism does not affect the authenticity of data [2]. In a study of Bouter et al., attendees of international research integrity conferences were invited to rank 60 research misbehaviors [57]. In spite of a perceived higher prevalence, plagiarism ranked behind data fabrication and falsification in terms of its impact on truth [57].

Concerning factors that determine plagiarism, most respondents indicated that intention mattered. Though there might be different motivations behind unintentional and intentional plagiarism, it is always difficult to detect intention, so this factor is not often considered relevant by guidance or policies about plagiarism $[8,9$, 58]. As a consequence, better strategies to address unintentional plagiarism should be designed.

Since the meaning of plagiarism is not always clearly understood, it is possible that some people did not know whether their own behaviors constituted plagiarism or not, which was supported by our findings: nearly one third of the respondents reported to have had moments doubting whether they had been plagiarizing. This shows that plagiarism is not always "black and white", and that grey zones persist (in contrast perhaps to fabrication and falsification, where things are more clearcut). This should be taken into account by those in charge of teaching or judging scientific integrity. Surveys in other regions also revealed the existence of confusion about what constitutes plagiarism $[18,59,60]$. Hence, systematic education on scientific writing and proper citations is needed $[59,61]$.

\section{Influences of demographic factors}

We found associations between mother tongue and responses to many questions. For example, compared with the group of other language speakers (whose mother tongue is neither English nor Chinese), more Chinesenative speakers tended to agree that length and part of the copied text mattered, while English-native speakers were less likely to think part mattered. This difference might be due to different levels of difficulty experienced when writing scientific articles in English, which is also supported by Biagioli [62]. As a consequence, the different proportions of English-native speakers in our respondents in Europe and China might have contributed to the different responses observed between both regions. Thus, we found that Chinese-native speakers tended to believe more frequently than English-native speakers that the type of copied text mattered, which was in accordance with the viewpoint held by some nonnative English speakers in Biagioli's study: appropriation of text in certain parts (such as the Introduction Section) from Anglophone papers would help, as long as the result is original [62]. Our study and that of Biagioli indicate that non-native English speakers understand the notion plagiarism differently from native speakers.

Our female respondents showed slightly more concerns with several practices, including idea plagiarism and self-plagiarism. Although several studies did not observe gender differences regarding perceptions or prevalence of research misconduct [61, 63], some scholars detected a difference [64-67] and attributed it to social and psychological differences between males and females $[68,69]$.

Having a PhD degree was associated with some responses. Liao et al. [30] found that participants with a $\mathrm{PhD}$ degree did not differ from other participants on their opinions towards academic misconduct. Nonetheless, in our present study, researchers with a $\mathrm{PhD}$ degree proved to be more self-confident with their understanding of plagiarism. In contrast, researchers without a $\mathrm{PhD}$ or not currently pursuing a $\mathrm{PhD}$ degree had a poorer understanding of image plagiarism and self-plagiarism, and more concerns with republishing one's thesis and reusing one's previously rejected research proposals. The differences above might be partly explained by the experience with practices and training on research when performing one's $\mathrm{PhD}$ research project [70].

Moreover, confidence increased with age. With more working years and research experience, senior researchers might have a better understanding of plagiarism. It has been reported that as years of study and working increased, tolerance toward plagiarism increased [69] while incidence of research misconduct declined $[59,65]$. Nevertheless, another study also pointed out that the knowledge about plagiarism did not increase with age and years of study [67]. As a consequence, we cannot overlook the importance of research integrity training for senior researchers.

In light of the fact that tolerance toward plagiarism varied across countries [71], it is surprising that international research experience of more than 6 months was 
hardly associated with understanding of plagiarism. One possible reason might be that the length of stay is not long enough to have any effect on researchers' understanding of plagiarism. In addition, the questionnaire did not investigate the countries in which the international research was conducted. It is possible that positive and negative effects were mixed, therefore no effect was observed in the present study.

\section{Limitations}

Compared to some other online surveys that also investigated plagiarism or other aspects of research integrity $[61,72-74]$, we had a low response rate $(4.2 \%)$. Despite the low numbers of respondents, we did observe a number of significant differences for some questions. The large geographical span might be one contributing factor of our low response rate. Besides, considering the large number of our target respondents, we sent invitation emails in bulks, which might have directed the invitation to the spam box of some potential respondents. Nevertheless, although we acknowledge that the response rate of our survey was low, the final number of respondents (more than 1 thousand) was considerable and, to our knowledge, higher than in any published study on the subject among established biomedical scientists.

The response rate of respondents in China was lower than for Europe. According to the first author's personal experience and reported evidence [75], emails are not a common way for daily communication in China. We could have asked the 46 institutions to send the invitations to their staff members on our behalf, but this procedure would have entailed considerable administrative implications and, more importantly, respondents might have had doubts about the anonymity of the survey, which would have affected the reliability of responses. This is why we chose the more time and effort demanding option of sending individual emails to potential participants (except in the case of our own university), in the knowledge that this would be at the expense of a low response rate. Furthermore, our response rate is in the same order of magnitude as in the studies on research integrity or research environment among Chinese researchers by Liao et al. [30] and Han et al. [76].

In addition to the drawbacks above, we made efforts to improve the response rate. We kept the questionnaire brief and narrowed down our scope to plagiarism rather than asking about many different types of misconduct. Nevertheless, in light of the low response rate, we should be aware of the influence of non-response bias. Those who answered our questionnaire might have had a better understanding of plagiarism than those who did not. In addition, a large proportion of the respondents had international research experience, which might have influenced their perceptions of plagiarism. Therefore, our results might be biased towards "the best case". In other words, if our survey revealed that well-educated and active biomedical researchers did not have an excellent understanding of plagiarism, we might presume that the understanding of other people may be even worse.

Although we developed the questionnaire on the basis of the Turnitin definition of plagiarism [27] and our previous work $[28,29]$, and carefully elaborated it, we acknowledge that it was not formally validated.

In the present work, we did not analyze the possible existence of differences in the perception of plagiarism within Europe, but such analyses are planned in the future.

\section{Practical implications}

Our survey reveals that the understanding of plagiarism, especially knowledge of subtle forms of plagiarism, is still lacking among biomedical researchers based in European and Chinese top universities. We also observed a lower tendency to perceive several specific practices as plagiarism among China-based biomedical researchers compared to Europe-based researchers. Such lack of knowledge may increase the risk of plagiarism. In consequence, to improve the ability to recognize and avoid various forms of plagiarism, education and training about knowledge of plagiarism should be enhanced, and accompanied by giving concrete examples of plagiarism practices $[23,59,61]$.

It is worth noting that the notion of plagiarism keeps developing and that boundaries of plagiarism have expanded a lot. More and more institutions and scholars start to discuss other forms of plagiarism, such as selfplagiarism $[38,77,78]$. In the future, as academic activity and intercultural communication increase, the understanding of plagiarism is very likely to be deepened.

In our opinion, avoiding plagiarism is more than just the avoidance of "copying and pasting". It should be a reflection of good research practices. The best strategy for avoiding plagiarism, as well as promoting good research practices, should be increasing transparency, especially when there is doubt. In practice, always indicate the source of your words, images, ideas and probably other forms of "inspirations".

\section{Conclusions}

Through our online survey among biomedical researchers in leading universities in Europe and China, we found that these researchers had a generally good knowledge of the most obvious forms of plagiarism, but doubts with other practices still existed. To conclude, a clearer working definition is needed among biomedical researchers to deal with grey zones.

Despite largely similar responses among biomedical researchers based in Europe and China, a lower likelihood 
to perceive certain practices as plagiarism was observed among China-based researchers. This may indicate that the risk of facing plagiarism offenses could be greater in China than in Europe. We recognize that the relatively low number of respondents, as well as their possibly selected nature, affect the generalizability of our study, especially where no differences were observed between Chinese and European respondents. Nevertheless, even though our survey revealed some practices of plagiarism to be less likely recognized as such by (a minority of) Chinese respondents than by European respondents, it also suggested the existence of many similarities between both groups, thus leading us to the cautious conclusion that our findings should not be interpreted as "Chinese researchers perceive plagiarism differently from European researchers." Our study represents a first endeavor to investigate empirically whether and how researchers in Europe and China differ in their perception of plagiarism.

\section{Supplementary information}

Supplementary information accompanies this paper at https://doi.org/10. 1186/s12910-020-00473-7.

Additional file 1. Survey on Perceptions of Plagiarism Definition. This

Additional file 2. Universities included in the survey. This file contains the list of 46 universities that were selected in this study. The biomedical researchers in these universities were invited to participate in our online survey.

Additional file 3. Invitation to the online survey. This file contains the invitation letter sent to the selected respondents in this study.

Additional file 4. Consistency analysis of practices in pairs. This file contains the result of consistency analysis that was performed to investigate the consistency within each respondent between the responses to different questions in Section 2.

\section{Abbreviation}

FFP: fabrication, falsification and plagiarism; OR(s): odds ratio(s); aOR(s): adjusted odds ratio(s); CI(s): confidence interval(s); SD: standard deviation

\section{Acknowledgements}

The authors would like to thank Ms. Annouschka Laenen at Leuven Biostatistics and Statistical Bioinformatics Centre for the statistical analysis she provided.

The authors would like to thank Prof. Marie-Christine Janssens, Prof. Mieke Clement and Prof. Herman Buelens of KU Leuven for their comments and suggestions on questionnaire improvement. Gratitude also goes to the colleagues at the Centre for Biomedical Ethics and Law, KU Leuven for their suggestions in the pilot study and the Chinese scholars Lusi Chen, Tianshu Wu and Shifu Peng for validating the Chinese translation of the questionnaire.

The authors are deeply grateful to all of the participants of the survey.

\section{Authors' contributions}

NY contributed to the conception and design of the work; and contributed significantly to the acquisition, analysis, and interpretation of data; and drafted the work. BN contributed significantly to the conception and design of the work; and contributed significantly to the analysis and interpretation of data; and substantively revised the work. KD contributed significantly to the conception and design of the work; and contributed to the analysis and interpretation of data; and substantively revised the work. All authors have read and approved the final manuscript; and have agreed both to be personally accountable for the author's own contributions and to ensure that questions related to the accuracy or integrity of any part of the work, even ones in which the author was not personally involved, are appropriately investigated and resolved.

\section{Funding}

This work was funded by China Scholarship Council (Grant No. 201406090164).

This funding body had no role in the design of this study, collection, analysis, interpretation of data, and in writing the manuscript.

\section{Availability of data and materials}

The datasets used during the current study are available from the corresponding author on reasonable request.

\section{Ethics approval and consent to participate}

The study was approved by the Social and Societal Ethics Committee of the KU Leuven (dossier G- 201708 885). Filling out the survey counts as informed consent to participate in this study, which was clearly indicated in the online questionnaire and approved by the Social and Societal Ethics Committee of the KU Leuven.

\section{Consent for publication}

Not applicable.

\section{Competing interests}

The authors declare that they have no competing interests.

\section{Author details}

${ }^{1}$ Department of Medical Humanities, School of Humanities, Southeast University, Nanjing 211189, China. ${ }^{2}$ Centre for Biomedical Ethics and Law, Department of Public Health and Primary Care, KU Leuven, Leuven, Belgium. ${ }^{3}$ Centre for Environment and Health, Department of Public Health and Primary Care, KU Leuven, Leuven, Belgium.

Received: 2 November 2019 Accepted: 14 April 2020

Published online: 01 June 2020

\section{References}

1. Anderson MS. Collective openness and other recommendations for the promotion of research integrity. Sci Eng Ethics. 2007;13(4):387-94.

2. Steneck NH. Fostering integrity in research: definitions, current knowledge, and future directions. Sci Eng Ethics. 2006;12(1):53-74.

3. China's medical research integrity questioned. Lancet. 2015;385:1365. https:// www.thelancet.com/journals/lancet/article/PIIS0140-6736(15)60700-0/fulltext.

4. The Lancet Oncology. Restoring confidence in research integrity. Lancet Oncol. 2015:16(8):871.

5. Titus SL, Wells JA, Rhoades LJ. Repairing research integrity. Nature. 2008;453: 980-2.

6. Bauchner H, Fontanarosa PB, Flanagin A, Thornton J. Scientific misconduct and medical journals. JAMA. 2018;320(19):1985-7.

7. ORI (The Office of Research Integrity). Definition of research misconduct http://ori.hhs.gov/definition-misconduct. Accessed October 28, 2015.

8. ALLEA (ALL European Academies). The European Code of Conduct for Research Integrity (revised edition). https://www.allea.org/wp-content/ uploads/2017/05/ALLEA-European-Code-of-Conduct-for-Research-Integrity2017.pdf. Accessed March 6, 2018.

9. NRC (National Research Council Canada). NRC Research Integrity Policy. https://www.nrc-cnrc.gc.ca/obj/doc/about-apropos/policies-politiques/ research_integrity-integrite_recherche/research_integrity.pdf. Accessed February 12, 2018.

10. Vinod KR, Sandhya S, Sathish KD, Harani A, Banji D, Banji OJF. Plagiarismhistory, detection and prevention. Hygeia.J.D.Med. 2011;3(1):1-4.

11. COPE (Committee on publication ethics). Plagiarism. https:// publicationethics.org/category/keywords/plagiarism. Accessed January 24, 2018.

12. ORI (The Office of Research Integrity). ORI Policy on Plagiarism. https://ori. hhs.gov/ori-policy-plagiarism. Accessed March 21, 2020. 
13. What is plagiarism? https://www.plagiarism.org/article/what-is-plagiarism. Accessed 24 Nov 2018.

14. Haitch R. Stealing or sharing? Cross-cultural issues of plagiarism in an opensource era. Teach Theol Relig. 2016;19(3):264-75.

15. Maxwell A, Curtis GJ, Vardanega L. Does culture influence understanding and perceived seriousness of plagiarism? Int J Educ Integr. 2008;4(2):25-40.

16. Kayaoğlu MN, Erbay \$̧, Flitner C, Salta D. Examining students' perceptions of plagiarism: a cross-cultural study at tertiary level. J Furt and High Educ. 2016; 40(5):682-705.

17. Pulverer B, Garner H. How to stop plagiarism. Nature. 2012;481:21-3.

18. Gullifer JM, Tyson GA. Who has read the policy on plagiarism? Unpacking students' understanding of plagiarism. Stud High Educ. 2014;39(7):1202-18

19. Hu G, Lei J. Investigating Chinese university students' knowledge of and attitudes toward plagiarism from an integrated perspective. Lang Learn. 2012:62(3):813-50.

20. Chien SC. Cultural constructions of plagiarism in student writing: teachers' perceptions and responses. Res Teach Engl. 2014;49(2):120-40.

21. Flowerdew J, Li Y. Language re-use among Chinese apprentice scientists writing for publication. Appl Linguist. 2007;28(3):440-65.

22. Ding Y. Text memorization and imitation: the practices of successful Chinese learners of English. System. 2007;35(2):271-80.

23. Heitman E, Litewka S. International perspectives on plagiarism and considerations for teaching international trainees. Urol Oncol. 2011;29(1):104-8.

24. Ehrich J, Howard SJ, Mu C, Bokosmaty S. A comparison of Chinese and Australian university students' attitudes towards plagiarism. Stud High Educ. 2016:41(2):231-46

25. Okonta Pl, Rossouw T. Misconduct in research: a descriptive survey of attitudes, perceptions and associated factors in a developing country. BMC Med Ethics. 2014;15(1):25

26. Pickard J. Staff and student attitudes to plagiarism at university college Northampton. Assess Eval High Educ. 2006;31(2):215-32.

27. Turnitin. The plagiarism spectrum. https://www.turnitin.com/static/ plagiarism-spectrum/. Accessed November 22, 2018.

28. Yi N, Nemery B, Dierickx K. Integrity in biomedical research: a systematic review of studies in China [published online may 2, 2018]. Sci Eng Ethics doi: 10.1007/s11948-018-0057-x.

29. Yi N, Nemery B, Dierickx K. Perceptions of research integrity and the Chinese situation: in-depth interviews with Chinese biomedical researchers in Europe [published online August 10, 2019] Account Res. doi: 10.1080/ 08989621.2019 .1652096

30. Liao Q, Zhang Y, Fan Y, et al. Perceptions of Chinese biomedical researchers towards academic misconduct: a comparison between 2015 and 2010. Sci Eng Ethics. 2018;24(2):629-45

31. LERU (League of European research universities). About LERU https://www leru.org/about-leru\#members. Accessed September 25, 2018.

32. Wikipedia. League of European Research Universities. https://en.wikipedia.org/ wiki/League_of_European_Research_Universities. Accessed March 12, 2018.

33. Ministry of Education of the People's Republic of China, Ministry of Finance of the People's Republic of China, National Development and Reform Commission of China [中华人民共和国教育部, 中华人民共和国财政部, 中华人民共和国国家发展改革委].教育部 财政部 国家发展改革委 关于 公布世界一流大学和一流学科建设高校及建设 学科名单的通知 Notice from the Ministry of Education and other national governmental departments announcing the list of double first class universities and disciplines. http://www.moe.gov.cn/srcsite/A22/moe 843/201709/ t20170921_314942.html. Accessed September 25, 2018. (Chinese)

34. Wikipedia. Double First Class University Plan. https:/en.wikipedia.org/wiki/Double_ First_Class_University_Plan. Published 2018. Accessed September 25, 2018.

35. von Elm E, Altman DG, Egger M, Pocock SJ, Gøtzsche PC, Vandenbroucke $J P$. The strengthening the reporting of observational studies in epidemiology (STROBE) statement: guidelines for reporting observational studies. PLoS Med. 2007;4(10):e296.

36. Clarke R. Plagiarism by academics: more complex than it seems. J Assoc Inf Syst. 2006;7(1):5

37. Silver I, Shaw A. No harm, still foul: concerns about reputation drive dislike of harmless plagiarizers. Cogn Sci. 2018:42:213-40.

38. Fusch P, Ness L, Booker J, Fusch G. The ethical implications of plagiarism and ghostwriting in an open society. J Soc Change. 2017;9(1):4

39. Baždarić K, Bilić-Zulle L, Brumini G, Petrovečki M. Prevalence of plagiarism in recent submissions to the Croatian medical journal. Sci Eng Ethics. 2012; 18(2):223-39.
40. Li Y. Text-based plagiarism in scientific writing: what Chinese supervisors think about copying and how to reduce it in students' writing. Sci Eng Ethics. 2013;19(2):569-83.

41. Leonard M, Schwieder D, Buhler A, Bennett DB, Royster M. Perceptions of plagiarism by STEM graduate students: a case study. Sci Eng Ethics. 2015; 21(6):1587-608

42. Introna L, Hayes N, Blair L, Wood E. Cultural attitude towards plagiarism. Lancaster University: Lancaster; 2003.

43. Pupovac V, Bilic-Zulle L, Mavrinac M, Petrovecki M. Attitudes toward plagiarism among pharmacy and medical biochemistry students-crosssectional survey study. Biochem Med (Zagreb). 2010;20(3):307-13.

44. ICMJE (International Committee of Medical Journal Editors). Recommendations for the Conduct, Reporting, Editing, and Publication of Scholarly Work in Medical Journals. http://www.icmje.org/icmjerecommendations.pdf. Accessed June 4, 2018.

45. ORI (The Office of Research Integrity). Duplicate (Dual) publications. https:// ori.hhs.gov/plagiarism-14. Accessed January 24, 2018.

46. Hvistendahl M. China's publication bazaar. Science. 2013;342:1035-9.

47. Tucker JD, Chang H, Brandt A, et al. An empirical analysis of overlap publication in Chinese language and English research manuscripts. PLoS One. 2011:6(7):e22149.

48. Hu Z, Wu Y. An empirical analysis on number and monetary value of ghostwritten papers in China. Curr Sci. 2013;105(9):1230-4.

49. Li D, Cornelis G. How do researchers perceive research misbehaviors? A transcultural case study of Chinese and Flemish researchers. Account Res. 2018:25(6):350-69.

50. Greenwood M, Walkem K, Smith LM, Shearer T, Stirling C. Postgraduate nursing student knowledge, attitudes, skills, and confidence in appropriately referencing academic work. J Nurs Educ. 2014;53(8):447-52.

51. Zhang $X$, Huo Z, Zhang $Y$. Detecting and (not) dealing with plagiarism in an engineering paper: beyond CrossCheck_a case. Sci Eng Ethics. 2014;20(2): 433-43.

52. Fierz K, Gennaro S, Dierickx K, Van Achterberg T, Morin KH, De Geest S. Scientific misconduct: also an issue in nursing science? J Nurs Scholarsh. 2014;46(4):271-80

53. Maurer H, Kappe F, Zaka B. Plagiarism: a survey. J Univers Comput Sci. 2006; 12(8):1050-84.

54. Bennett KK, Behrendt LS, Boothby JL. Instructor perceptions of plagiarism: are we finding common ground? Teach Psychol. 2011;38(1):29-35.

55. Kim H, Markus HR. Deviance or uniqueness, harmony or conformity? A cultural analysis. J Pers Soc Psychol. 1999;77(4):785-800.

56. Roberts DL, St John FAV. Estimating the prevalence of researcher misconduct: a study of UK academics within biological sciences. PeerJ. 2014;2:e562.

57. Bouter LM, Tijdink J, Axelsen N, Martinson BC, Ter Riet G. Ranking major and minor research misbehaviors: results from a survey among participants of four world conferences on research integrity. Res Integr Peer Rev. 2016;1:17. https://doi.org/10.1186/s41073-016-0024-5.

58. ORI (The Office of Research Integrity). ORI Policy on Plagiarism. https://ori. hhs.gov/ori-policy-plagiarism. Accessed January 24, 2018.

59. Okonta P, Rossouw T. Prevalence of scientific misconduct among a group of researchers in Nigeria. Dev World Bioeth. 2013;13(3):149-57.

60. Dawson MM, Overfield JA. Plagiarism: do students know what it is? Biosci Educ. 2006;8(1):1-15.

61. Pupovac V, Prijić-Samaržija S, Petrovečki M. Research misconduct in the Croatian scientific community: a survey assessing the forms and characteristics of research misconduct. Sci Eng Ethics. 2017;23(1):165-81.

62. Biagioli M. Recycling texts or stealing time?: plagiarism, authorship, and credit in science. Int J Cult Prop. 2012;19(3):453-76.

63. Fanelli $D$, Costas $R$, Larivière V. Misconduct policies, academic culture and career stage, not gender or pressures to publish, affect scientific integrity. PLoS One. 2015;10(6):e0127556.

64. Yang SC. Attitudes and behaviors related to academic dishonesty: a survey of Taiwanese graduate students. Ethics Behav. 2012;22(3):218-37.

65. Martinson BC, Anderson MS, Crain LA, De Vries R. Scientists' perceptions of organizational justice and self-reported misbehaviours. J Empir Res Hum Res Ethics. 2006;1(1):51-66.

66. Fanelli D. How many scientists fabricate and falsify research? A systematic review and meta-analysis of survey data. PLoS One 2009;4(5):e5738. doi:10. 1371/journal.pone.0005738

67. Varghese J, Jacob M. Do medical students require education on issues related to plagiarism? Indian J Med Ethics. 2015;12(2):82-7. 
68. Jereb E, Urh M, Jerebic J, et al. Gender differences and the awareness of plagiarism in higher education. Soc Psychol Educ. 2018;21:409.

69. Hu G, Lei J. Chinese university students' perceptions of plagiarism. Ethics Behav. 2015;25(3):233-55

70. Vasconcelos SMR, Masuda H, Sorenson M, Prosdocimi F, Palácios M, Watanabe $\mathrm{E}$, et al. Plagiarism in Brazil: a perspective of $25,000 \mathrm{PhD}$ holders across the sciences. 2019. https://www.biorxiv.org/content/10.1101/ 825026v1.full.pdf. Unrefereed preprint.

71. Pupovac V, Fanelli D. Scientists admitting to plagiarism: a meta-analysis of surveys. Sci Eng Ethics. 2015;21:1331-52.

72. Tijdink JK, Verbeke R, Smulders YM. Publication pressure and scientific misconduct in medical scientists. J Empir Res Hum Res Ethics. 2014;9(5):6471.

73. Nylenna M, Fagerbakk F, Kierulf P. Authorship: attitudes and practice among Norwegian researchers. BMC Med Ethics. 2014;15(1):53.

74. Godecharle S, Fieuws S, Nemery B, Dierickx K. Scientists still behaving badly? A survey within industry and universities. Sci Eng Ethics. 2017;24(6):1697717 .

75. Twinova. WeChat instead of email newsletter in China-the definitive guide. https://www.twinova.com/email-dead-long-live-wechat/. Accessed November 25, 2018

76. Han X, Appelbaum RP. China's science, technology, engineering, and mathematics (STEM) research environment: a snapshot. PLoS One. 2018; 13(4):e0195347.

77. ORI (The Office of Research Integrity). Self plagiarism. https://ori.hhs.gov/ plagiarism-13. Accessed January 24, 2018.

78. Horbach SPJM, Halffman W. The extent and causes of academic text recycling or self-plagiarism. Res Policy. 2019;48(2):492-502.

\section{Publisher's Note}

Springer Nature remains neutral with regard to jurisdictional claims in published maps and institutional affiliations.

Ready to submit your research? Choose BMC and benefit from:

- fast, convenient online submission

- thorough peer review by experienced researchers in your field

- rapid publication on acceptance

- support for research data, including large and complex data types

- gold Open Access which fosters wider collaboration and increased citations

- maximum visibility for your research: over $100 \mathrm{M}$ website views per year

At $\mathrm{BMC}$, research is always in progress.

Learn more biomedcentral.com/submissions 